\title{
Experimental Study of Cyclic Bending Failure for Round-hole Tubes with a Redundant Round Hole in the Same Direction but Different Cross Sections
}

\author{
Kuo-Long Lee ${ }^{1}$, Wen-Fung Pan $^{2 *}$ \\ 1. Department of Innovative Design and Entrepreneurship Management, Far East University, Tainan 744, \\ Taiwan \\ 2. Department of Engineering Science, National Cheng Kung University, Tainan 701, Taiwan \\ E-mail: z7808034@email.ncku.edu.tw (Corresponding author)
}

Received: 31 January 2020; Accepted: 1 March 2020; Available online: 31 March 2020

\begin{abstract}
This paper presents the influence of a redundant round hole in the same direction but different cross sections on the response and failure of round-hole 6061-T6 aluminum alloy tubes subjected to cyclic bending. In this study, round-hole 6061-T6 aluminum alloy tubes with a constant hole diameter of $6 \mathrm{~mm}$ were drilled to obtain a redundant round hole in the same hole direction but different cross sections. The experimental results revealed that the moment-curvature relationship exhibited an almost steady loop from the beginning of the first cycle. The redundant round hole showed minimal influence on the moment-curvature relationship. However, the ovalizationcurvature relationship demonstrated an asymmetrical, increasing, ratcheting and bow pattern along with the bending cycle, while the redundant round hole showed a significant influence on this relationship. In addition, six groups of round-hole 6061-T6 aluminum alloy tubes were tested, the controlled curvature-number of bending cycles required to ignite failure relationships on double logarithmic coordinates exhibited nonparallel straight lines. Finally, a theoretical model was proposed for simulating the controlled curvature-number of cycles to ignite failure. The simulation result was compared with experimental test data, which showed generally good agreement.

Keywords: Round-hole 6061-T6 aluminum alloy tubes; Redundant hole; Different cross sections; Cyclic bending; Moment; Curvature; Ovalization; Number of bending cycles required to ignite failure.
\end{abstract}

\section{Introduction}

A round-hole tube is a tube with a circular hole drilled through, as shown in Fig. 1. Round-hole tubes are often used as connections in parts of cars, locomotives, or bicycles. When a round-hole tube is submitted to a bending load, the circular cross section will gradually change to an elliptical shape with the increase of the bending degree. This will cause the bending rigidity of the tube to gradually decrease, which is called degradation phenomenon. A physical quantity called ovalization is employed to quantify the degradation phenomenon, which is the reduction of the outer diameter $\left(\Delta D_{0}=D_{0}-D\right)$ divided by the original outer diameter $\left(D_{0}\right)$, as shown in Fig. 2. In cyclic bending loads, the ovalization increases with the number of bending cycles. Finally, when a certain number of bending cycles is reached and the ovalization reaches a certain critical value, the round-hole tube will undergo fracture failure.

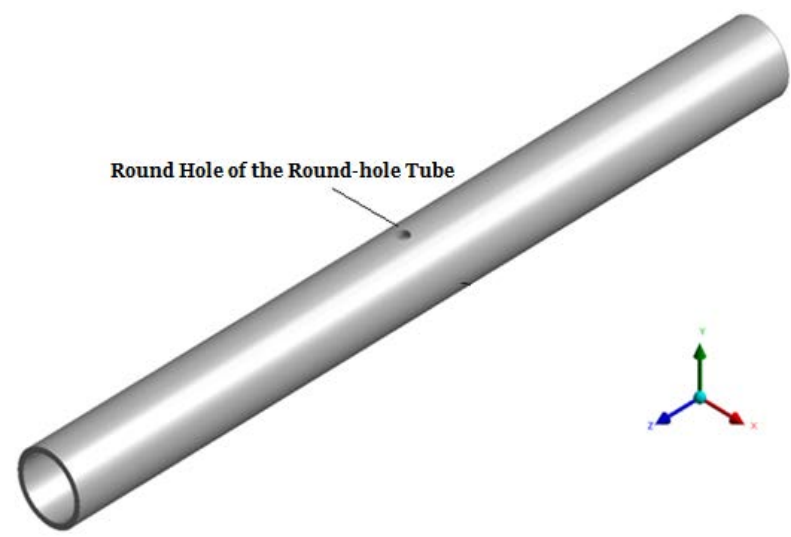

Fig. 1. A schematic drawing of a round-hole tube 


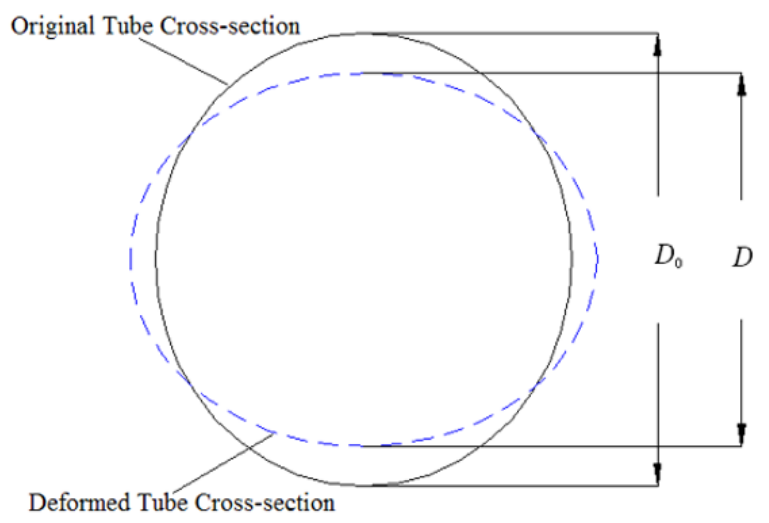

Fig. 2. Deformation of the tube's cross section for a circular tube under bending

In 1998, Pan et al. began a series of experimental and theoretical studies on tubes subjected to bending or cyclic bending with different loading and geometry conditions. Pan and Her [1] experimentally studied the curvature rate effect on the response and collapse of SUS304 stainless steel tubes submitted to cyclic bending and discovered that increasing the curvature rate increased the degree of hardening. Later, Pan and Fan [2] studied the effect of the prior curvature-rate at the preloading stage on subsequent creep (moment is kept constant for a period of time) or relaxation (curvature is kept constant for a period of time) behavior. Lee et al. [3] tested thin-walled tubes with different diameter-to-thickness ratios subjected to cyclic bending. Four groups of specimens, each with a distinct diameter-to-thickness ratio, were tested, and four parallel straight lines were obtained when the controlled curvature-number of bending cycles required to ignite buckling relationships were plotted on double logarithmic coordinates. Pan and Lee [4] examined the effect of the mean curvature on the response of tubes submitted to cyclic bending; this effect was investigated by considering three different curvature ratios (minimum curvature/ maximum curvature). Chang et al. [5] studied the viscoplastic cyclic bending response and collapse of 316L stainless steel tubes; in their research, the endochronic theory and the principle of virtual work were used to simulate the relevant behaviors. Chang and Pan [6] conducted cyclic bending experiments on the deterioration and buckling of circular tubes with different outer diameters. This investigation yielded a new formula for predicting the buckling life of circular tubes submitted to cyclic bending.

In 2010, Pan et al. began an experimental and analytical investigation on the cyclic bending response and failure of notched tubes. Lee et al. [7] examined the cyclic bending variations in ovalization of sharp-notched SUS304 stainless steel tubes. Later, Lee [8] investigated the cyclic bending collapse of circular tubes with different notch depths; this work proposed an empirical formula for predicting the number of bending cycles required to ignite buckling. Thereafter, Lee et al. [9] experimentally inspected the cyclic bending response and collapse of sharpnotched SUS304 stainless steel tubes subjected to cyclic bending with different curvature rates. Three different curvature rates, $0.003,0.03$ and $0.3 \mathrm{~m}^{-1} \mathrm{~s}^{-1}$, were used to highlight the related behavior. Lee et al. [10] studied the pure bending creep and relaxation response of sharp-notched SUS304 stainless steel tubes. The Bailey-Norton law was modified for simulating the creep curvature-time relationships and relaxation moment-time relationships. Chung et al. [11] explored the cyclic bending response and buckling of sharp-notched 6061-T6 aluminum alloy tubes. An empirical formulation was proposed for describing the controlled curvature-number of bending cycles required to ignite buckling relationships. However, all investigations of notched tubes were focused on the circumferential sharp notch. Later, Lee et al. [12] examined the cyclic bending behavior of local sharp-notched 6061-T6 aluminum alloy tubes. The sharp notch was a local sharp cut. In addition, the moment-curvature and ovalization-curvature relationships were analyzed using finite-element ANSYS. Thereafter, Lee et al. [13] explored the cyclic bending response and failure of local sharp-notched SUS304 stainless steel tubes. The sharp notch was a local sharp groove. The moment-curvature relationships were similar to those tested by Lee et al. [9], however, the ovalization-curvature relationships were quite different.

In the present study, round-hole 6061-T6 aluminum alloy tubes with a redundant round hole in the same hole direction ( $x$-direction) but different cross sections subjected to cyclic bending were experimentally investigated (Fig. 3). The round hole diameter of the round-hole 6061-T6 aluminum alloy tubes were fixed of $6 \mathrm{~mm}$. The redundant round hole was drilled in the same direction but different cross section with a hole diameter of $2 \mathrm{~mm}$. A tube-bending machine and curvature-ovalization measurement apparatus were employed to conduct curvaturecontrolled cyclic bending tests. The quantities of moment, curvature, and ovalization were measured by the testing devices. Additionally, the number of bending cycles required to ignite failure was also recorded. 


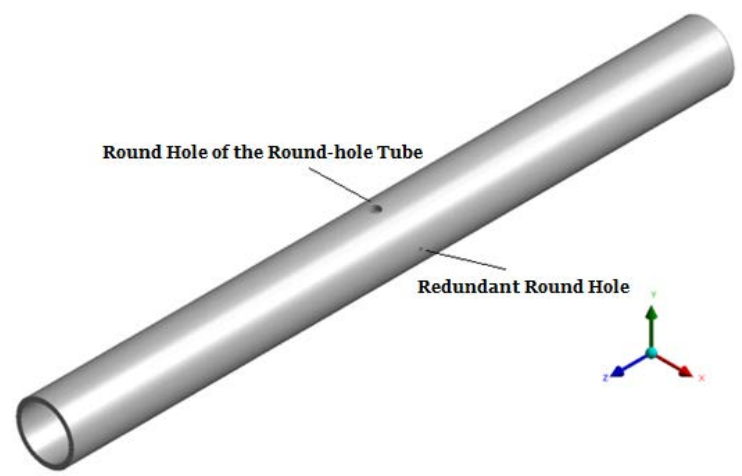

Fig. 3. A schematic drawing of a round-hole tube with a redundant round hole

\section{Experiments}

The tube-bending machine and the curvature-ovalization measurement apparatus were employed to conduct curvature-controlled cyclic bending tests on round-hole 6061-T6 aluminum alloy tubes with a redundant round hole. The bending device, measurement apparatus, materials, specimens, and test procedures are stated below.

\subsection{Experimental devices}

Fig 4 depicts a schematic drawing of the specially constructed tube-bending machine. It is a four-point bending machine capable of applying monotonic, reverse, and cyclic bending. The bending moment is obtained according to the signal from two load cells. A detailed description of the tube-bending machine can be found in many papers (Pan and Her [1]; Pan and Fan [2]; Lee et al. [3]).

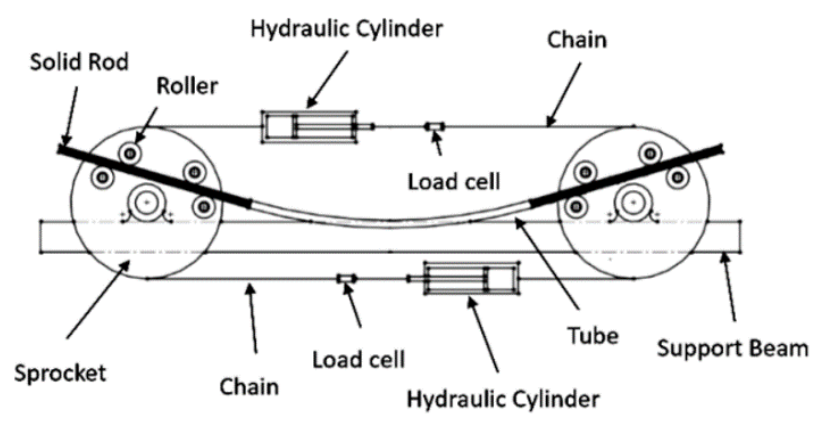

Fig. 4. A schematic drawing of the tube-bending machine

Fig. 5 demonstrates a schematic drawing of the curvature-ovalization measurement apparatus (COMA). The light-weight COMA can be placed in the middle of the tube. Two side-inclinometers are used to measure the angle changes of tubes during bending. The tube's curvature can be determined by a simple calculation. In addition, the upper magnetic detector and lower magnetic block in the central portion of the COMA are used to measure the ovalization of the tube's cross section. A detailed explanation of the COMA can be found in the study by Pan et al. [14].

\subsection{Material and specimens}

Round-hole 6061-T6 aluminum alloy tubes with a redundant round hole were used for the cyclic bending tests. The tubes' chemical composition (weight \%) is Mg (0.937), Si (0.535), Fe (0.139), Zn (0.098), Mn (0.022), Cr $(0.022), \ldots$, and a few other trace elements, with the remainder being Al. The mechanical properties of this material are as follows: the ultimate stress $\left(\sigma_{\mathrm{u}}\right)=320 \mathrm{MPa}$, the $0.2 \%$ strain offsetting yield stress $\left(\sigma_{0}\right)=285 \mathrm{MPa}$, and the percent elongation $\left(\% \varepsilon_{\mathrm{f}}\right)=11 \%$.

The original 6061-T6 aluminum alloy tube with $D_{\mathrm{o}}=35.0 \mathrm{~mm}$ and $t=3.0 \mathrm{~mm}$ was drilled to obtain a roundhole tube with a hole diameter of $6 \mathrm{~mm}$. Next, a redundant round hole with a hole diameter of $2 \mathrm{~mm}$ in the same direction ( $x$-direction) but different cross section was drilled. Fig. 6 demonstrates the dimensional drawing of the round-hole tube with a redundant hole at different cross sections. The round hole of the round-hole tube is on the A-A cross section. The round hole direction is in $y$-direction (fixed). However, the redundant round hole is on the B-B cross section. The redundant round hole direction is in $x$-direction (fixed). In this study, six horizontal 
distances $(X), 0,10,0,30,40$, and $50 \mathrm{~mm}$ from the A-A cross section, were considered. Note that $X=0 \mathrm{~mm}$ means the redundant round hole is on the A-A cross section.

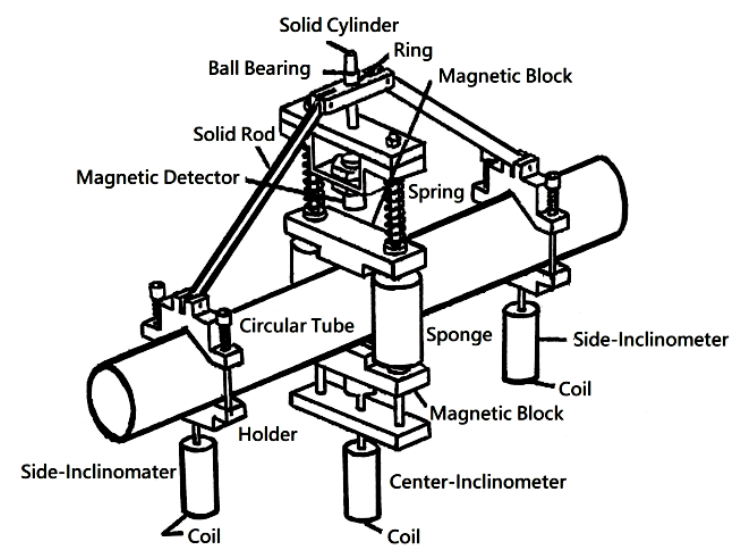

Fig. 5. A schematic drawing of the COMA
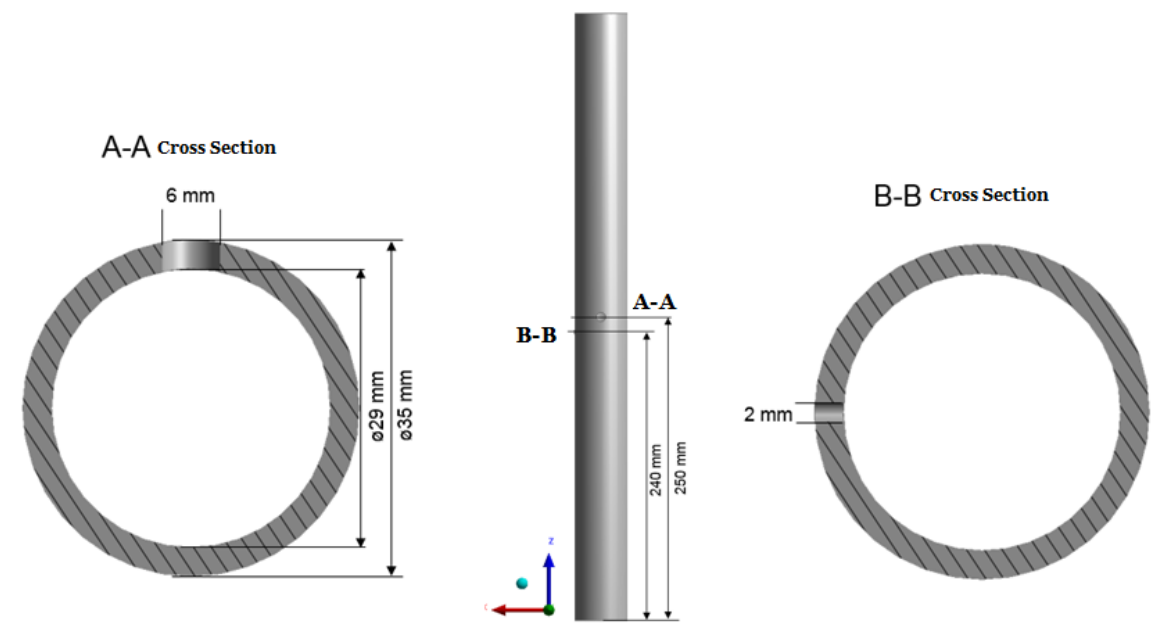

Fig. 6. A schematic drawing of a round-hole tube with a redundant round hole at $X=10 \mathrm{~mm}$

\subsection{Test procedures}

The experiments were curvature-controlled cyclic bending tests with a constant curvature rate of $0.03 \mathrm{~m}^{-1} \mathrm{~s}^{-1}$. The moment was measured by two load cells settled in the tube-bending machine (Fig. 4). The curvature and ovalization were measured by the COMA in Fig. 5. Simultaneously, the number of cycles required to ignite failure was also recorded.

\section{Experimental results and discussion}

\subsection{Mechanical response}

Fig. 7 depicts an experimentally determined cyclic moment $(M)$-curvature $(\kappa)$ curve for round-hole 6061-T6 aluminum alloy tube with a redundant round hole at $X=10 \mathrm{~mm}$ submitted to cyclic bending. The controlled curvatures were from $+0.4 \mathrm{~m}^{-1}$ to $-0.4 \mathrm{~m}^{-1}$. The $M-\kappa$ response exhibited an almost closed and stable loop from the first bending cycle. Because the redundant holes were small and localized, the $M-\kappa$ curves for different $X$ were nearly identical. Therefore, the $M-\kappa$ curves for different $X$ are not shown in this paper.

Figs. 8(a)-8(f) respectively demonstrate the experimentally determined cyclic ovalization $\left(\Delta D_{0} / D_{0}\right)-$ curvature $(\kappa)$ relationship for round-hole 6061-T6 aluminum alloy tubes with a redundant round hole at $X=0,10,20,30$, 40 , and $50 \mathrm{~mm}$ subjected to cyclic bending. The controlled curvatures were also from $+0.4 \mathrm{~m}^{-1}$ to $-0.4 \mathrm{~m}^{-1}$. The $\Delta D_{\mathrm{o}} / D_{0}-\kappa$ relationships showed an asymmetrical, ratcheting, increasing, and bow trend with the increase in the number of bending cycles. In addition, the amounts of $\Delta D_{0} / D_{0}$ were shown for the fifth cycle at the controlled curvature equaled to $-0.4 \mathrm{~m}^{-1}$. It was observed that a redundant round hole at $X=0 \mathrm{~mm}$ had the largest value of $\Delta D_{\mathrm{o}} / D_{0}$. Thus, it had a lowest number of bending cycles required to ignite failure. In contrast, a redundant round 
hole at $X=40 \mathrm{~mm}$ had the smallest value of $\Delta D_{\mathrm{o}} / D_{\mathrm{o}}$, thus, it had a highest number of bending cycles required to ignite failure.

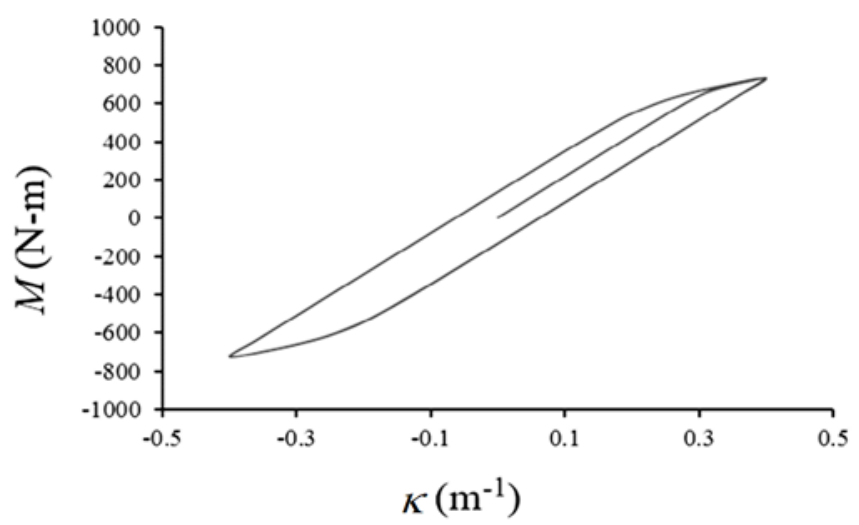

Fig. 7. Experimental $M-\kappa$ curve for round-hole 6061-T6 aluminum alloy tube with a redundant round hole at $X=10 \mathrm{~mm}$ under cyclic bending

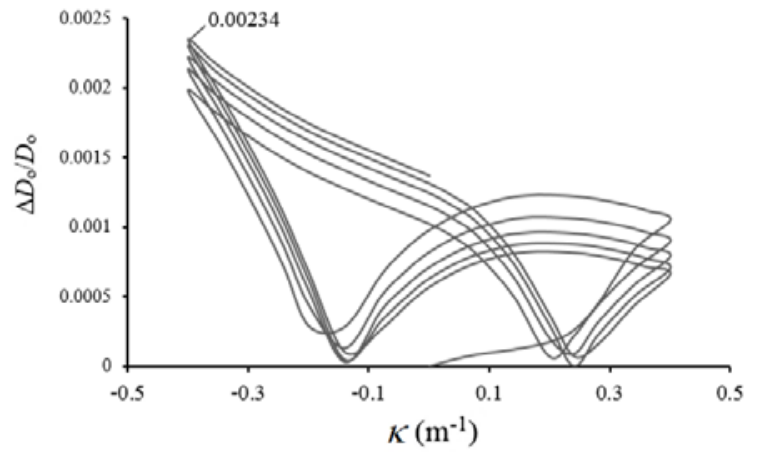

(a)

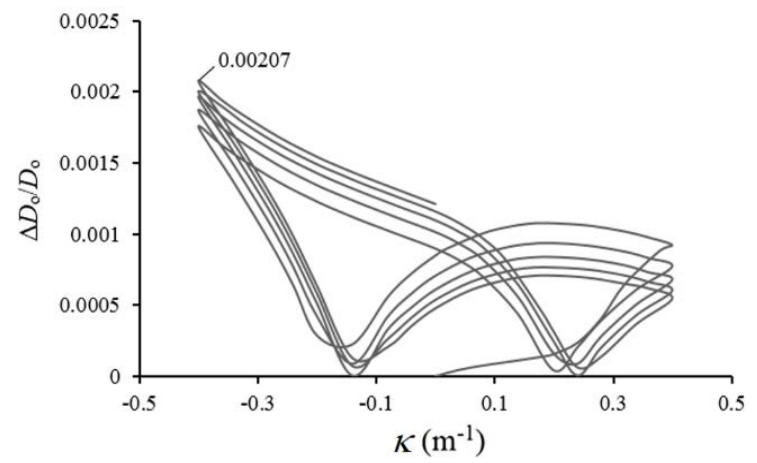

(c)

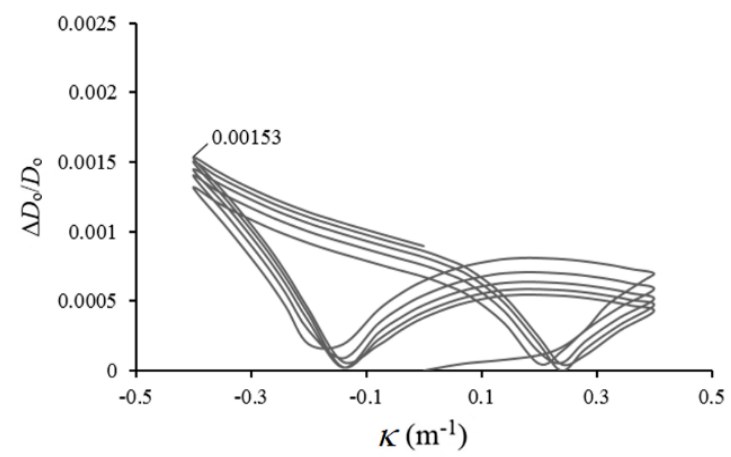

(e)

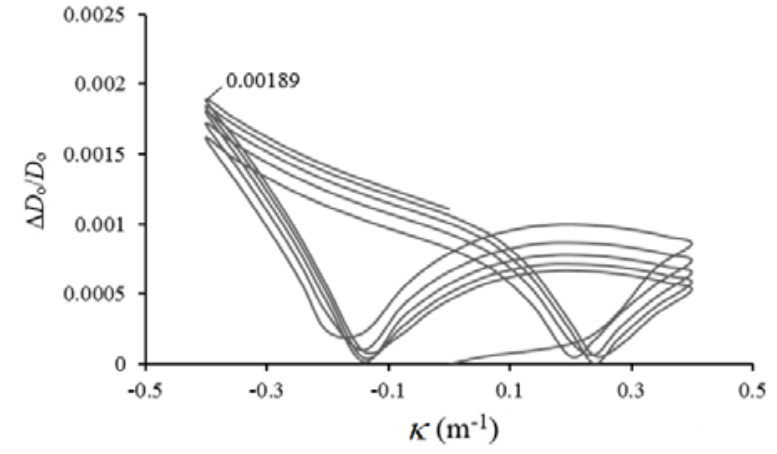

(b)

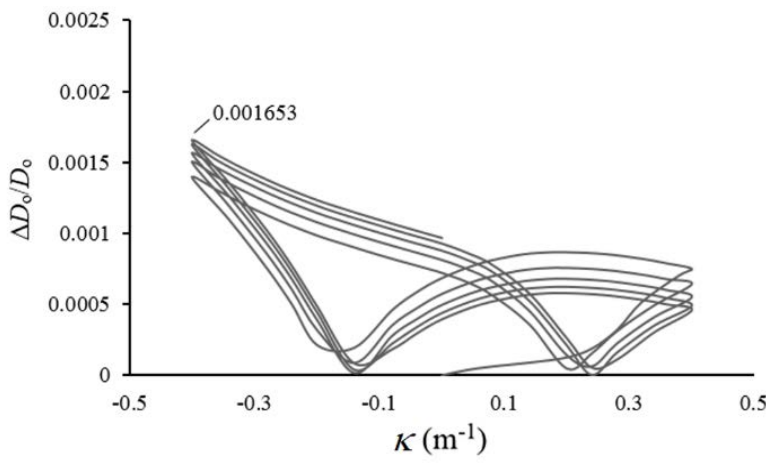

(d)

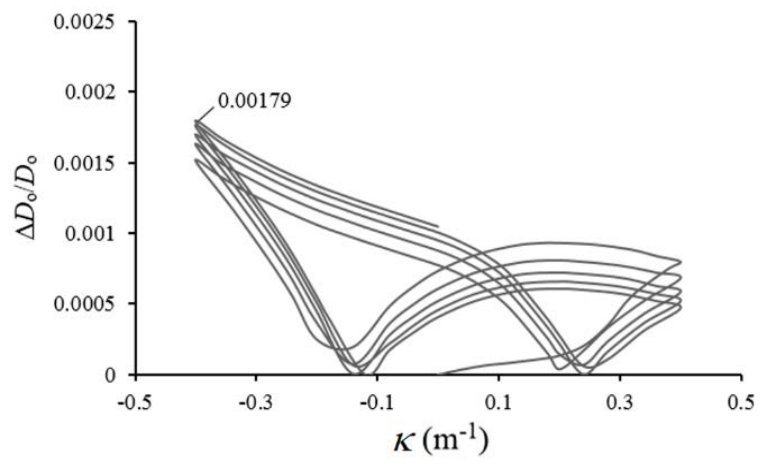

(f)

Fig. 8. Experimental $\Delta D_{\mathrm{o}} / D_{\mathrm{o}}-\kappa$ curves for round-hole 6061-T6 aluminum alloy tubes with a redundant round hole at $X=$ (a) 0, (b)10, (c) 20, (d) 30, (e) 40, and (f) $50 \mathrm{~mm}$ under cyclic bending 


\subsection{Failure}

Fig. 9 shows the experimental result of normalized controlled curvature $\left(\kappa_{\mathrm{c}} / \kappa_{\mathrm{o}}\right)$ versus number of bending cycles required to ignite failure $\left(N_{\mathrm{f}}\right)$ for round-hole 6061-T6 aluminum alloy tube with a redundant round hole at $X=0$, $10,20,30,40$, and $50 \mathrm{~mm}$ subjected to cyclic bending. Note that the definition of the $\kappa_{\mathrm{o}}$ is $t / D_{\mathrm{o}}^{2}$ (Kyriakides and Shaw [15]). Subsequently, the experimental data in Fig. 9 were plotted on double logarithmic coordinates, and six nonparallel straight lines were observed in Fig. 10. Note that the straight lines were determined by the least square method.

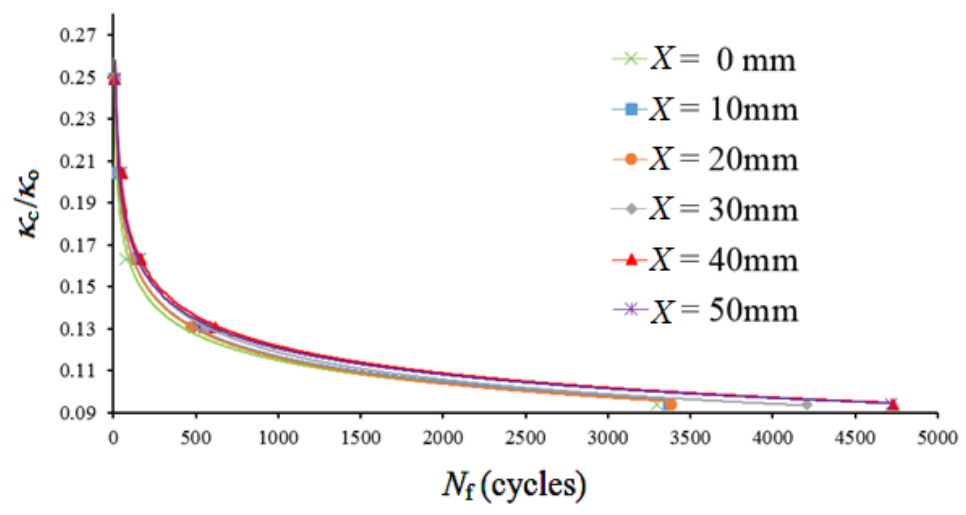

Fig. 9. Experimental $\kappa_{\mathrm{c}} / \kappa_{\mathrm{o}}-N_{\mathrm{f}}$ curves for round-hole 6061-T6 aluminum alloy tube with a redundant round hole at $X=0,10,20,30,40$, and $50 \mathrm{~mm}$ subjected to cyclic bending

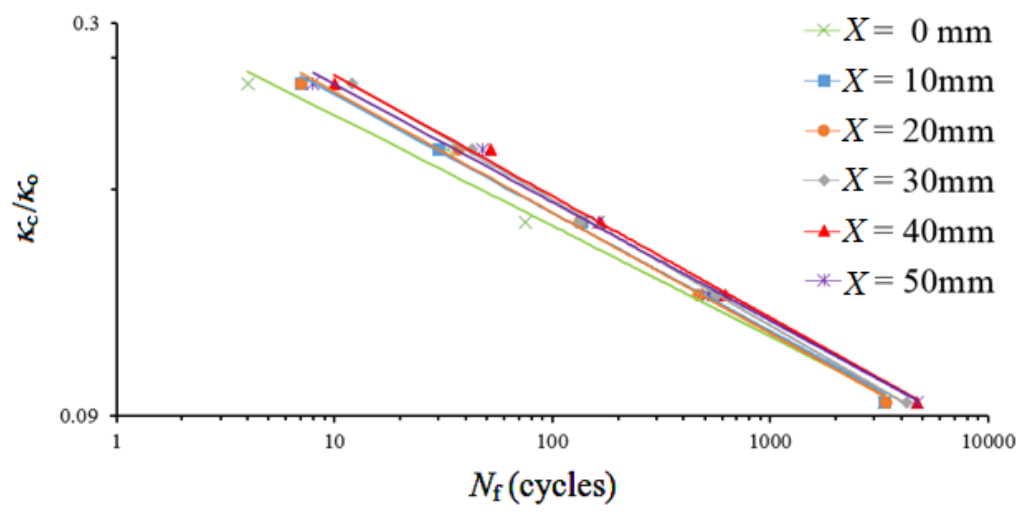

Fig. 10. Experimental $\kappa_{\mathrm{c}} / \kappa_{\mathrm{o}}-N_{\mathrm{f}}$ curves for round-hole 6061-T6 aluminum alloy tube with a redundant round hole at $X=0,10,20,30,40$, and $50 \mathrm{~mm}$ subjected to cyclic bending on double logarithmic coordinates

Lee et al. [16] proposed an empirical formulation for simulating the relationship between $\kappa_{\mathrm{c}} / \kappa_{\mathrm{o}}$ and $N_{\mathrm{f}}$ of roundhole 6061-T6 aluminum alloy tubes subjected to cyclic bending to be:

$$
\kappa_{\mathrm{c}} / \kappa_{\mathrm{o}}=C\left(N_{\mathrm{f}}\right)^{-\alpha} \quad \text { or } \quad \log \kappa_{\mathrm{c}} / \kappa_{\mathrm{o}}=\log C-\alpha \log N_{\mathrm{f}},
$$

where $C$ and $\alpha$ are the material parameters. The $C$ value is the quantity of $\kappa_{\mathrm{c}} / \kappa_{\mathrm{o}}$ by letting $N_{\mathrm{f}}=1$, while the $\alpha$ value is the slope of the line on double logarithmic coordinates. Fig. 11 demonstrates the six values of $C$ for $X=0,10$, 20, 30, 40 and $50 \mathrm{~mm}$ in orange solid circles. It was observed that two linear relationships were respectively found for $X=0,10,20,30 \mathrm{~mm}$ and $X=30,40,50 \mathrm{~mm}$. Therefore, the $C-X$ relationship was proposed as:

$$
C=c_{1} X+c_{2}, \quad 0 \mathrm{~mm} \leq X \leq 30 \mathrm{~mm},
$$

And

$$
C=c_{3} X+c_{4}, \quad 30 \mathrm{~mm} \leq X \leq 50 \mathrm{~mm},
$$

where $c_{1}, c_{2}, c_{3}$ and $c_{4}$ are materal constants. In this study, the magnitudes of $c_{1}, c_{2}, c_{3}$ and $c_{4}$ were respectively determined in Fig. 11 to be $0.0056,0.8233,-0.0031$ and 1.0927. 


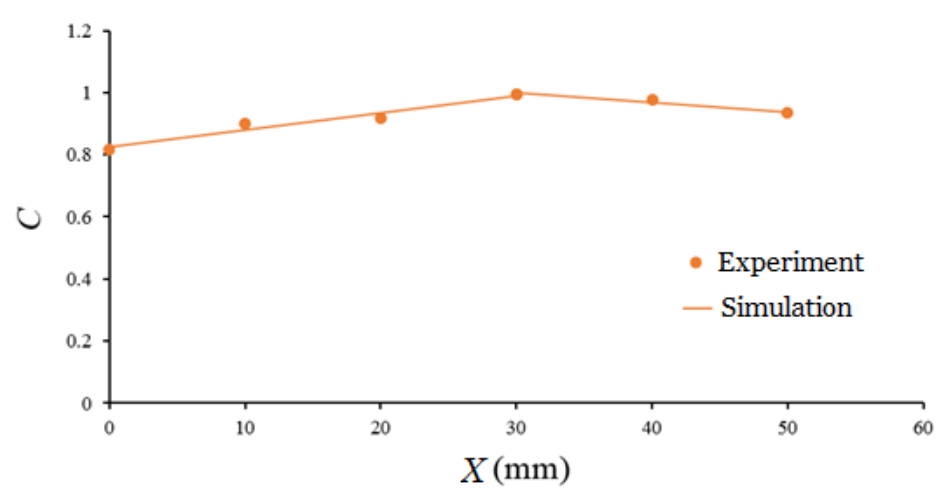

Fig. 11. The relationship between $C$ and $X$

Fig. 12 demonstrates the six values of $\alpha$ for $X=0,10,20,30,40$ and $50 \mathrm{~mm}$ in blue solid circles. It was observed that two linear relationships were respectively found for $X=0,10,20,30 \mathrm{~mm}$ and $X=30,40,50 \mathrm{~mm}$. Therefore, the $\alpha-X$ relationship was proposed as:

$$
\alpha=a_{1} X+a_{2} \quad 0 \mathrm{~mm} \leq X \leq 30 \mathrm{~mm}
$$

and

$$
\alpha=a_{3} X+a_{4} \quad 30 \mathrm{~mm} \leq X \leq 50 \mathrm{~mm}
$$

where $a_{1}, a_{2}, a_{3}$ and $a_{4}$ are materal constants. In this study, the magnitude of $a_{1}, a_{2}, a_{3}$ and $a_{4}$ were respectively determined in Fig. 12 to be $-0.0007,-0.1683,0.0006$ and -0.2077 . Finally, using Eqs. (1)-(5), the simulated relationships between $\kappa_{\mathrm{c}} / \kappa_{\mathrm{o}}$ and $N_{\mathrm{f}}$ for round-hole 6061-T6 aluminum alloy tube with a redundant round hole at $X$ $=0,10,20,30,40$ and $50 \mathrm{~mm}$ under cyclic bending on double logarithmic coordinates are respectively shown in Figs. 13-18. It can be seen that the simulated result correlates well with the experimental finding.

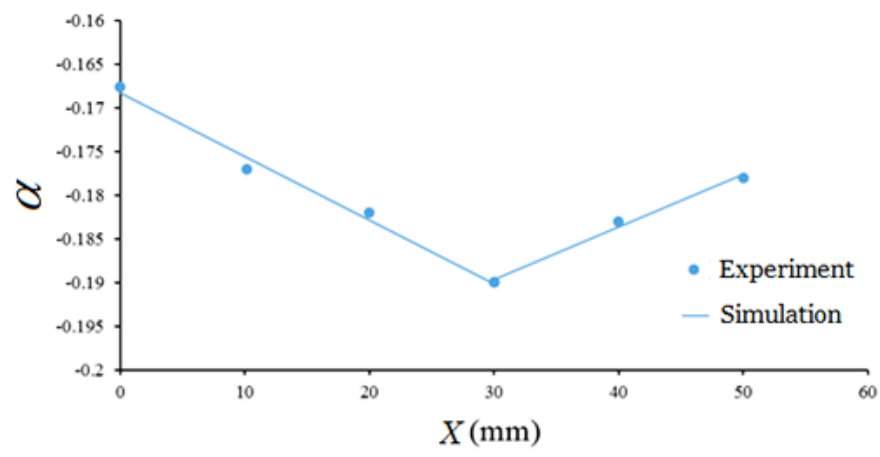

Fig. 12. The relationship between $\alpha$ and $X$

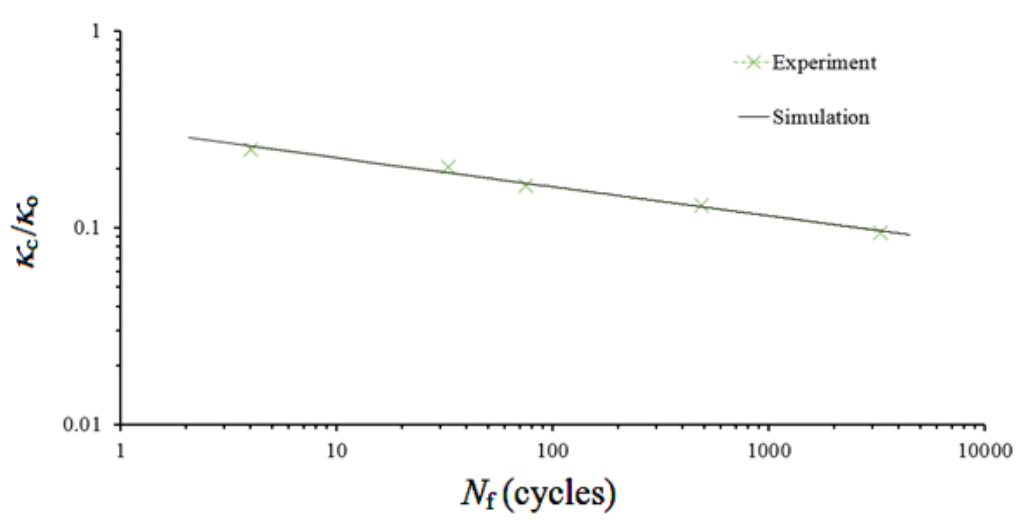

Fig. 13. Experimental and simulated $\kappa_{\mathrm{c}} / \kappa_{\mathrm{o}}-N_{\mathrm{f}}$ curves for round-hole 6061-T6 aluminum alloy tube with a round redundant hole at $X=0 \mathrm{~mm}$ under cyclic bending on double logarithmic coordinates 


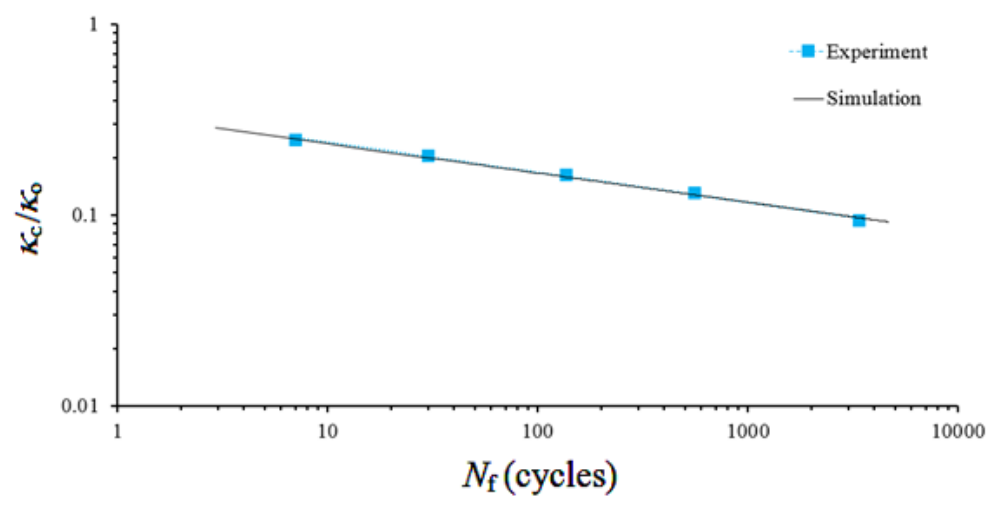

Fig. 14. Experimental and simulated $\kappa_{\mathrm{c}} / \kappa_{\mathrm{o}}-N_{\mathrm{f}}$ curves for round-hole 6061-T6 aluminum alloy tube with a round redundant hole at $X=10 \mathrm{~mm}$ under cyclic bending on double logarithmic coordinates

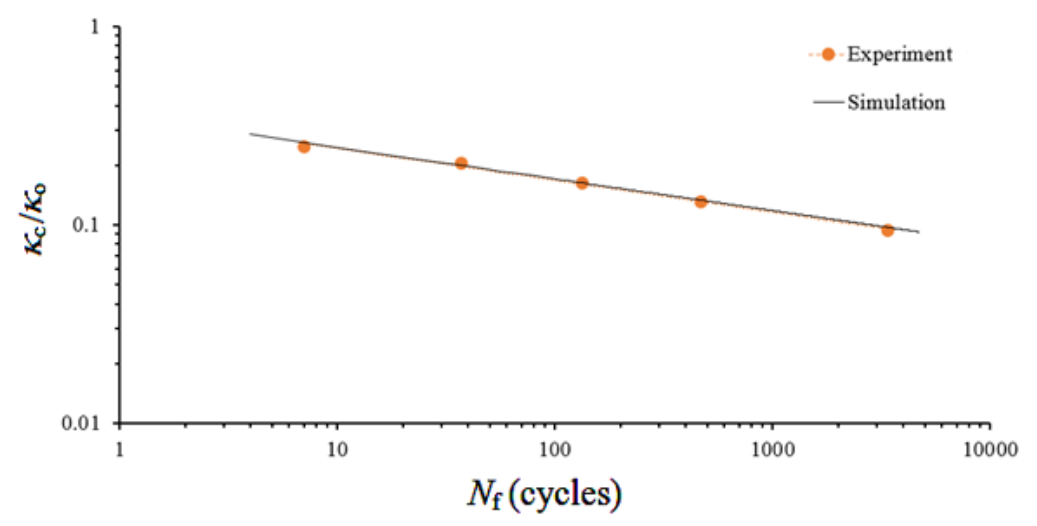

Fig. 15. Experimental and simulated $\kappa_{\mathrm{c}} / \kappa_{\mathrm{o}}-N_{\mathrm{f}}$ curves for round-hole 6061-T6 aluminum alloy tube with a round redundant hole at $X=20 \mathrm{~mm}$ under cyclic bending on double logarithmic coordinates

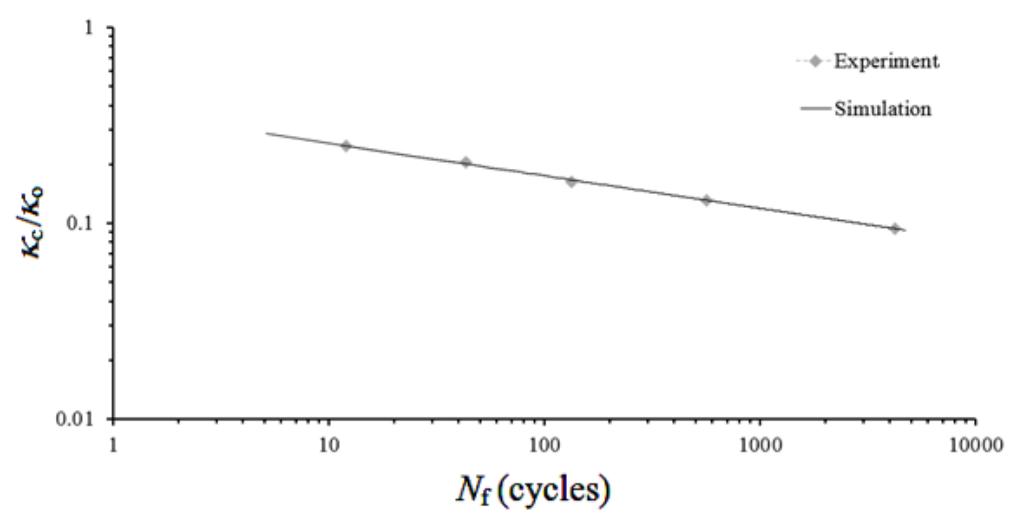

Fig. 16. Experimental and simulated $\kappa_{\mathrm{c}} / \kappa_{\mathrm{o}}-N_{\mathrm{f}}$ curves for round-hole 6061-T6 aluminum alloy tube with a round redundant hole at $X=30 \mathrm{~mm}$ under cyclic bending on double logarithmic coordinates

\section{Conclusions}

This study investigated the influence of a redundant round hole in the same direction but different cross sections on the response and failure of round-hole 6061-T6 aluminum alloy tubes subjected to cyclic bending. According to the experimental and theoretical results, the following conclusions were drawn:

1) The experimental moment-curvature relationship for round-hole 6061-T6 aluminum alloy tubes with a redundant round hole in the same direction but different cross sections subjected to cyclic bending displayed a closed and stable hysteresis loop from the first cycle. The redundant round hole was small and local. Hence, different cross sections had almost no influence on the moment-curvature relationship. 


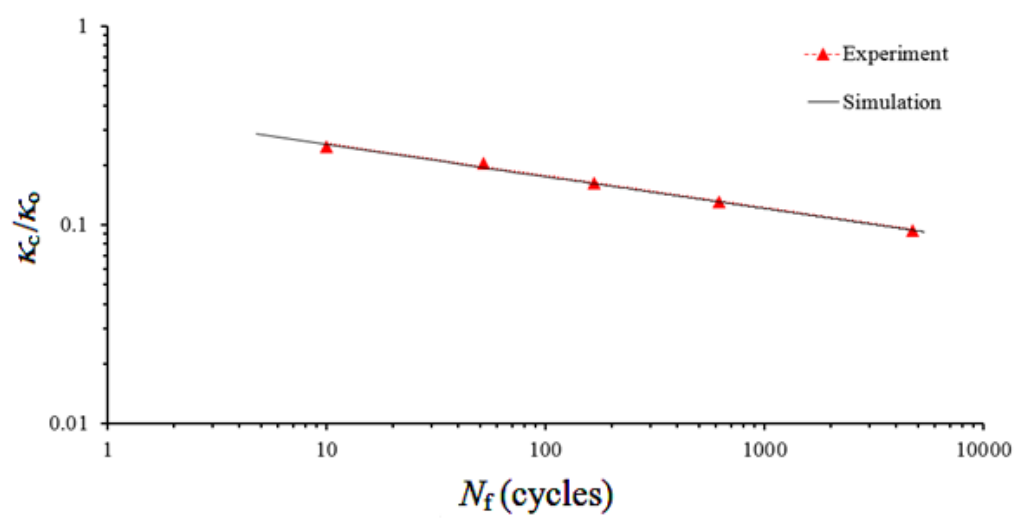

Fig. 17. Experimental and simulated $\kappa_{\mathrm{c}} / \kappa_{\mathrm{o}}-N_{\mathrm{f}}$ curves for round-hole 6061-T6 aluminum alloy tube with a round redundant hole at $X=40 \mathrm{~mm}$ under cyclic bending on double logarithmic coordinates

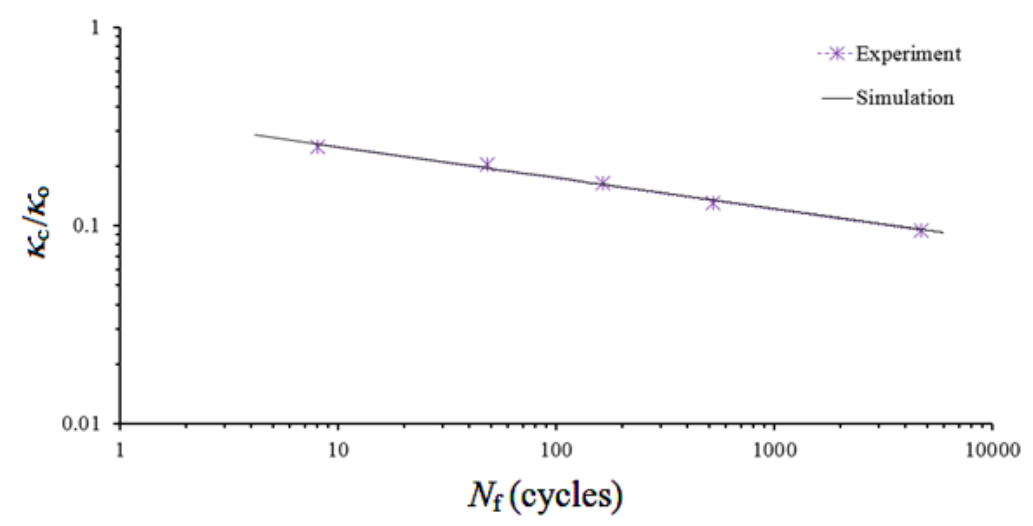

Fig. 18. Experimental and simulated $\kappa_{\mathrm{c}} / \kappa_{\mathrm{o}}-N_{\mathrm{f}}$ curves for round-hole 6061-T6 aluminum alloy tube with a round redundant hole at $X=50 \mathrm{~mm}$ under cyclic bending on double logarithmic coordinates

2) The experimental ovalization-curvature relationship for round-hole 6061-T6 aluminum alloy tubes with a redundant round hole in the same direction but different cross sections subjected to cyclic bending revealed an asymmetrical, increasing, ratcheting, and bow trend with the increase in the number of cycles. The redundant round hole showed a significant influence on the ovalization-curvature relationships. In addition, a redundant round hole at $X=0 \mathrm{~mm}$ had the largest ovalization. However, a redundant round hole at $X=40 \mathrm{~mm}$ had the smallest ovalization.

3) The empirical formula of Eq. (1) was used to simulate normalized controlled curvature-number of bending cycles required to ignite failure relationships for round-hole 6061-T6 aluminum alloy tubes with a redundant round hole in the same direction but different cross sections subjected to cyclic bending. According to the experimental data in Fig. 11. parameter $C$ was proposed in Eqs. (2) and (3). In addition, according to the experimental data in Fig. 12. parameter $\alpha$ was proposed in Eqs. (4) and (5). It can be seen in Figs. 13-18 that the simulated results obtained by Eqs. (1)-(5) were in good agreement with the experimental findings.

\section{Acknowledgement}

This study was conducted under the authority of the project MOST 108-2221-E-006-183, supported by the Ministry of Science and Technology. Here, we are very grateful for the support provided by the Ministry.

\section{References}

[1] Pan WF, Her YS. Viscoplastic collapse of thin-walled tubes under cyclic bending. Journal of Engineering Materials and Technology. 1998;120(4):287-290.

[2] Pan WF, Fan CH. An experimental study on the effect of curvature-rate at preloading stage on subsequent creep or relaxation of thin-walled tubes under pure bending. JSME International Journal Series A. 1998;41(4): 525-531. 
[3] Lee KL, Pan WF, Kuo JN. The influence of the diameter-to-thickness ratio on the stability of circular tubes under cyclic bending. International Journal of Solids and Structures. 2001;38(14):2401-2413.

[4] Pan WF, Lee KL. The effect of mean curvature on the response and collapse of thin-walled tubes under cyclic bending. JSME International Journal Series A. 2002;45(2):309-318.

[5] Chang KH, Hsu CM, Sheu SR, Pan WF. Viscoplastic response and collapse of 316L stainless steel tubes under cyclic bending. Steel and Composite Structures. 2005;5(5):359-374.

[6] Chang KH, Pan WF. Buckling life estimation of circular tubes under cyclic bending. International Journal of Solids and Structures. 2009;46(2):254-270.

[7] Lee KL, Hung CY, Pan WF. Variation of ovalization for sharp-notched circular tubes under cyclic bending. Journal of Mechanics. 2010;26(3):403-411.

[8] Lee KL. Mechanical behavior and buckling failure of sharp-notched circular tubes under cyclic bending. Structural Engineering and Mechanics. 2010;34(3):367-376.

[9] Lee KL, Hsu CM, Pan WF. Viscoplastic collapse of sharp-notched circular tubes under cyclic bending. Acta Mechanica Solida Sinica. 2013;26(6):629-641.

[10] Lee KL, Hsu CM, Pan WF. Response of sharp-notched circular tubes under bending creep and relaxation. Mechanical Engineering Journal. 2014;1(1):1-14.

[11] Chung CC, Lee KL, Pan WF. Collapse of sharp-notched 6061-T6 aluminum alloy tubes under cyclic bending. International Journal of Structural Stability and Dynamics. 2016;26(7):1550035.

[12] Lee KL, Chang KH, Pan WF. Failure life estimation of sharp-notched circular tubes with different notch depths under cyclic bending. Structural Engineering and Mechanics. 2016;60(3):387-404.

[13] Lee KL, Chang KH, Pan WF. Effects of notch depth and direction on stability of local sharp-notched circular tubes subjected to cyclic bending. International Journal of Structural Stability and Dynamics. 2018;18(7): 1850099.

[14] Pan WF, Wang TR, Hsu CM. A curvature-ovalization measurement apparatus for circular tubes under cyclic bending. Experimental Mechanics. 1998;38(2):99-102.

[15] Kyriakides S, Shaw PK. Inelastic buckling of tubes under cyclic bending. Journal of Pressure Vessel and Technology. 1987;109(2):169-178.

[16] Lee KL, Chung CC, Pan WF. On the failure of round-hole tubes under cyclic bending. Journal of the Chinese Society of Mechanical Engineers. 2019;40(6):663-673.

(C) 2020 by the author(s). This work is licensed under a Creative Commons Attribution 4.0 International License (http://creativecommons.org/licenses/by/4.0/). Authors retain copyright of their work, with first publication rights granted to Tech Reviews Ltd. 